\title{
Neurotrophic factors in tension-type headache
}

\author{
Fatores neurotróficos na cefaleia do tipo tensional \\ Renan B. Domingues' ${ }^{1}$, Halina Duarte', Natália P. Rocha², Antonio L. Teixeira1,2
}

\begin{abstract}
Neurotrophic factors (NF) are involved in pain regulation and a few studies have suggested that they may play a pathophysiological role in primary headaches. The aim of this study was to investigate NF levels in patients with tension type headache (TTH). We carried out a cross sectional study including $48 \mathrm{TTH}$ patients and 48 age and gender matched controls. Beck Depression and Anxiety Inventories, and Headache Impact Test were recorded. Serum levels of NF were determined by ELISA. There were not significant differences between NF levels between TTH patients and controls. Patients with chronic and episodic TTH had not significant differences in NF levels. The presence of headache at the time of evaluation did not significantly alter the levels of NF. Depression and anxiety scores as well as headache impact did not correlate with NF levels. Our study suggest that the serum levels of NF are not altered in TTH.
\end{abstract}

Keywords: tension-type headache, neurotrophic factors, depression, anxiety.

\section{RESUMO}

Os fatores neurotróficos (FN) participam da regulação da dor e podem ter um papel na fisiopatologia das cefaleias peimárias. 0 objetivo do presente estudo foi avaliar os níveis séricos de FN em pacientes com cefaleia do tipo tensional (CTT). Foi realizado corte transversal com 48 pacientes com CTT e 48 controles pareados por gênero e idade. Os inventários de Beck para depressão e ansiedade, bem como o inventário de impacto da cefaleia foram aplicados. Os níveis séricos de FN foram determinados por ELISA. Não houve diferenças significativas entre níveis de FN entre pacientes com TTH e controles, bem como entre pacientes com TTH episódica e crônica. Presença de cefaleia no momento da avaliação não alterou os níveis séricos de FN. Os escores de depressão, ansiedade e impacto da cefaleia não se correlacionaram com os níveis de FN. Nosso estudo sugere que não há alteração dos níveis de FN na TTH.

Palavras-chave: cefaleia do tipo tensional, fatores neurotróficos, depressão, ansiedade.

Tension-type headache (TTH) is the most prevalent headache and is associated with a high socioeconomical impact ${ }^{1}$. It has been suggested that episodic TTH (ETTH) is mainly due to peripheral mechanisms such as muscle tenderness. Central mechanisms leading to reduced pain threshold and sensitization in the trigeminal nucleus, thalamus, or somatosensory cortex are probably related with chronic TTH (CTTH) ${ }^{2}$. However, the precise mechanisms determining ETTH and the conversion of ETTH to CTTH remain largely unknown.

Neurotrophic factors (NF) are a unique group of polypeptides responsible for neuron survival, axon growth, dendrite prunning, and the expression of essential proteins for the neuronal functioning. NF are classified in different families according to functional and structural characteristics, such as the glial cell line-derived neurotrophic factor (GNDF) family and the neurotrophin super-family that includes the brainderived neurotrophic factor (BDNF), the nerve-growth factor (NGF), the neurotrophin-3 (NT-3), and the neurotrophin-4/5 $(\mathrm{NT}-4 / 5)^{3}$. NF may play a role in nociception by regulating peripheral sensitivity of nociceptors and by modulating the central processing of nociceptive information ${ }^{4}$. Considering that peripheral nociceptors and central processing of nociceptive information are both potentially involved in the pathophysiology of TTH, it is reasonable to hypothetize that NF may be involved in TTH pathogenesis.

The association between NF and primary headaches has already been investigated. Reduced BDNF and NGF platelet levels have been described in patients with migraine and chronic daily headache $(\mathrm{CDH})^{5}$. BDNF was shown to be increased during migraine and cluster headache attacks ${ }^{6,7}$. Increased cerebrospinal fluid (CSF) levels of NGF and BDNF,

\footnotetext{
'Universidade Federal de Minas Gerais, Programa de Pós-Graduação em Neurociências, Belo Horizonte MG, Brazil;

${ }^{2}$ Universidade Federal de Minas Gerais, Faculdade de Medicina, Laboratório Interdisciplinar de Investigação Médica, Belo Horizonte MG, Brazil.

Correspondence: Renan B. Domingues; Rua Maringá, 8; 05020-020 São Paulo, SP, Brasil; E-mail: contato@renandomingues.med.br

Conflict of interest: There is no conflict of interest to declare.

Support: CNPq and Fapemig, Brazil.

Received 04 September 2014; Received in final form 22 December 2014; Accepted 13 January 2015.
} 
and reduced levels of GDNF were found in patients with $\mathrm{CDH}^{8,9,10,11}$. A recent study showed that patients with frequent ETTH had not significant different BDNF levels as compared with controls ${ }^{6}$. No previous study has investigated differences in NF between ETTH and CTTH.

The aim of this study was to compare GDNF, BDNF, NGF, NT-3, and NT-4/5 serum levels between TTH patients and controls. We also aimed to compare NF levels between patients with ETTH and CTTH, and to evaluate the correlation of NF levels with psychiatric symptoms and headache impact in TTH patients.

\section{METHOD}

\section{Patients and procedures}

This was a cross-sectional study involving patients with TTH and controls without headache, recruited from June to December 2011. TTH patients were enrolled from a public outpatient headache clinic in Brazil. All patients were recruited during their first attendance at the clinic. Headache diagnosis was based on the International Classification on Headache Disorders $-2^{\text {nd }}$ edition and was made by a neurologist with expertise in headache ${ }^{12}$. Control subjects were recruited through active search among healthy volunteers that were accompanying patients attending consults at the same outpatient clinic. Only subjects with no history of primary headaches were included in the control group. The minimal age for the inclusion of patients and control subjects was 18 years old. Exclusion criteria included: active inflammatory, infectious, allergic, autoimmune, hepatic, neurodegenerative, and neoplasic diseases, as well as pregnant women and people in use of corticosteroids or immunosuppresant drugs. This study received full approval by the Ethics Committee on Research of the institution in which patients were recruited, and informed consent was obtained from each participant.

Demographic (age, race, and marital status) and headache features (lenght of disease, frequency of attacks in the last month) as well as the body mass index (BMI) were recorded. Headache impact test (HIT-6) was recorded from patients ${ }^{13}$. Anxiety was evaluated with the Beck Anxiety Inventory (BAI) ${ }^{14}$ and depression with the Beck Depression Inventory $(\mathrm{BDI})^{15}$. According to the BAI score patients and controls were classified as having mild (8 to 15), moderate (16 to 25 ), or severe anxiety symptoms ${ }^{14}$. According to the BDI score the subjects were classified as having minimal ( 0 to 9 ), mild (10 to 18 ), moderate (19 to 29 ), or severe (30 to 63 ) depressive symptoms ${ }^{15}$.

\section{NF assessment}

Eight mililites of blood were drawn from each subject at the moment of the clinical assessment. The blood was immediately centrifuged at $3,000 \mathrm{~g}$ for $10 \mathrm{~min}, 4^{\circ} \mathrm{C}$, twice. Serum was collected and stored at $-70^{\circ} \mathrm{C}$ until assayed. Serum levels of GDNF, BDNF, NGF, NT-3, and NT-4/5 were measured by enzyme-linked immunossorbent assay (ELISA) according to the manufacturer procedure (R\&D Systems, Minneapolis, MN, USA). All samples were assayed in duplicate. Concentration was expressed as $\mathrm{pg} / \mathrm{mL}$. Detection limits were defined as $5 \mathrm{pg} / \mathrm{mL}$ for BDNF and $10 \mathrm{pg} / \mathrm{mL}$ for the other NF.

\section{Statistical analysis}

The data were analyzed with the SPSS, version 15.0 for Windows. The confidence interval was of $95 \%$ and the significance level was set at $\mathrm{p}<0.05$. Verification of normal distribution of data was performed using the Kolmogorov-Smirnov test. Mann-Whitney was used for the medians comparisons of continuous data. Categorical data were compared using Chi-square test. Correlations were evaluated with Spearman test.

\section{RESULTS}

Ninety-six subjects were included in the study, being 48 patients with TTH and 48 controls without headache history. Forty-two (87.5\%) out of 48 patients with TTH were classified as having ETTH and 6 (12.5\%) as having CTTH. Fouteen (29.1\%) of the patients referred headache at the time of the evaluation. There were no differences of age, gender, ethnic distribution, marital status and BMI between TTH patients and controls (Table). Patients with CTTH were older than patients with ETTH $(61.17 \pm 11.09 \times 37.86 \pm 17.09, \mathrm{p}=0.029)$. No significant differences of ethnic groups, gender, and marital status distributions were found between patients with ETTH and CTTH ( $p=0.359,0.289$, and 0.592, respectively). Median BDI and BAI scores were significantly higher in TTH patients than in controls ( $p=0.041$ and 0.014 , respectively). BDI and BAI scores did not significantly differ between patients with CTTH and ETTH ( $p=1.0$ and 0.663, respectively).

The levels of GDNF, BDNF, NGF, NT-3, and NT-4/5 were not significantly different between controls and patients with TTH ( $\mathrm{p}=0.838,0.838,0.153,0.540,0.540$, respectively) (Table, Figure). There were not significant diferrences in GDNF, BDNF, NGF, NT-3, NT-4/5 levels between patients with ETTH and CTTH ( $p=0.190,0.663,0.663,0.663,0.663$, respectively). TTH patients with and without pain at the moment of the evaluation had not significant different levels of GNDF ( $p=0.751)$, BNDF ( $p=0.751)$ NGF ( $p=0.751)$, NT-3 $(\mathrm{p}=0.751)$, and NT-4/5 ( $\mathrm{p}=0.751)$.

Increasing age was significantly correlated with GDNF (correlation coeficient $=-0.312, \mathrm{p}=0.002$ ), NT-3 (correlation coeficient $=-0.213, \mathrm{p}=0.037$ ), and NT-4/5 (correlation coeficient $=-0.270, p=0.008)$, but not correlated with BDNF ( $p=0.127$ ) and NGF ( $p=0.120)$. GDNF, BDNF, NGF, NT-3, and NT-4/5 were not significantly correlated with HIT-6 ( $p=0.107,0.096,0.171,0.200$, and 0.298, respectively) nor with the number of headache days per month $(p=0.786,0.663$, $0.568,0.348$, and 0.837 , respectively). 
Table. Clinical and demographic data of TTH patients and controls.

\begin{tabular}{|c|c|c|c|}
\hline & Controls $(n=48)$ & TTH $(n=48)$ & $\mathrm{p}$ \\
\hline Age & $40.35 \pm 14.38$ & $40.77 \pm 18.13$ & 0.838 \\
\hline \multicolumn{4}{|l|}{ Gender } \\
\hline Female (\%) & $43(89.6)$ & $43(89.6)$ & \\
\hline Male (\%) & $5(10.4)$ & $5(10.4)$ & \\
\hline Marital Status & & & 0.292 \\
\hline Married (\%) & $21(43.75)$ & $15(31.25)$ & \\
\hline Single (\%) & $27(56.25)$ & $33(68.75)$ & \\
\hline Ethnic distribution & & & 0.342 \\
\hline White (\%) & $20(41.7)$ & $25(52.1)$ & \\
\hline Brown (\%) & $23(47.9)$ & $16(33.3)$ & \\
\hline Black (\%) & $5(10.4)$ & $7(14.6)$ & \\
\hline $\mathrm{BMI}$ & $25.4(17.7-49.3)$ & $25.6(18.8-45.7)$ & 0.920 \\
\hline Time of disease (years) & - & $13(1-51)$ & \\
\hline Age of onset (years) & - & $18(5-58)$ & \\
\hline Frequency of attacks (per month) & - & $3(1-30)$ & \\
\hline HIT-6 & - & $51.5(36-70)$ & \\
\hline BDI score & $4(0-31)$ & $7.5(0-22)$ & 0.041 \\
\hline BAl score & $4(0-19)$ & $8(0-54)$ & 0.014 \\
\hline GNDF (pg/mL) & $184.9(0-1959.6)$ & $472(5.1-7311.8)$ & 0.838 \\
\hline $\mathrm{BDNF}(\mathrm{pg} / \mathrm{mL})$ & $7700.4(3474.6-13644)$ & $6768(4083.5-11584.6)$ & 0.153 \\
\hline $\operatorname{NGF}(p g / m L)$ & $169.1(0-1406.8)$ & $296.2(0-4737.4)$ & 0.838 \\
\hline NT-3 (pg/mL) & $270.9(0-3300.2)$ & $669.6(7.9-6141.7)$ & 0.540 \\
\hline $\mathrm{NT}-4 / 5(\mathrm{pg} / \mathrm{mL})$ & $61.3(0-400)$ & $228.8(0-5270)$ & 0.54 \\
\hline
\end{tabular}

There were not significant correlations between BDI score and GDNF ( $p=0.905), \operatorname{BDNF}(\mathrm{p}=0.561)$, NGF ( $\mathrm{p}=0.608)$, NT-3 $(p=0.771)$, and NT-4/5 $(p=0.690)$. BAI score was not significantly correlated with GDNF $(p=0.360)$ BDNF $(p=0.456)$, NGF ( $p=0.720)$, NT-3 ( $p=0.250)$, and NT-4/5 ( $p=0.199)$. Four (8.3\%) TTH patients had moderate to severe anxiety symptosm, while 44 (91.7\%) had no or mild anxiety symptoms according to the BAI score. The NF levels were not significantly different between these two groups (GDNF, $p=0.602$; NGF, $\mathrm{p}=0.602 ; \mathrm{NT} 3, \mathrm{p}=0.117$; NT4/5, $\mathrm{p}=0.602$; BDNF, $\mathrm{p}=0.602$ ). Forty three TTH patients had minimal to mild depressive symptoms $(89.6 \%)$ and $5(10.4 \%)$ had moderate to severe depressive symptoms according to BDI score. No significant difference was found for GDNF ( $p=1.000), \operatorname{NGF}(p=1.000)$, NT3 $(\mathrm{p}=1.000)$, NT4/5 $(\mathrm{p}=1.000)$, and BDNF $(\mathrm{p}=1.000)$ levels between these groups.

\section{DISCUSSION}

We did not find significant differences in serum levels of GDNF, BDNF, NGF, NT-3, and NT-4/5 between TTH patients and controls. This finding is in line with a previous study showing that BDNF serum levels in TTH patients were not different from control subjects ${ }^{6}$. This previous study included only 6 patients with ETTH without pain at the time of evaluation and 22 healthy controls.
We did not find any significant difference in serum NF levels between patients with ETTH and CTTH; although only 6 patients with CTTH were included in the analysis. It is possible that the small number of patients in this latter group precluded the finding of any significant difference. A relationship between increased NF levels and chronic migraine was previously shown ${ }^{8,9}$, suggesting that the upregulation of these molecules production may contribute to neuroplastic changes that may be implicated in migraine chronificaton. In patients with TTH the relationship between NF and TTH chronification remains unclear and future studies with larger number of CTTH patients are still required.

In our study, TTH patients with and without pain did not have significant differences in NF levels. In other primary headache disorders, such as migraine and cluster headache, the levels of NF were registered to be higher during pain attacks ${ }^{6,7}$. It is possible that this is not the case for TTH. We did not find any correlation between NF levels and TTH functional impact nor with the number of headache days per month, suggesting that NF are not related with TTH severity. One possible explanation for these negative results is that NF are not really involved in TTH pathogenesis. Another possibility is that plasma levels of NF does not really reflect central nervous system NF changes in TTH. In some studies assessing the relationship between NF and primary headaches, the altered NF levels were found only in the $\mathrm{CSF}^{8}$. 

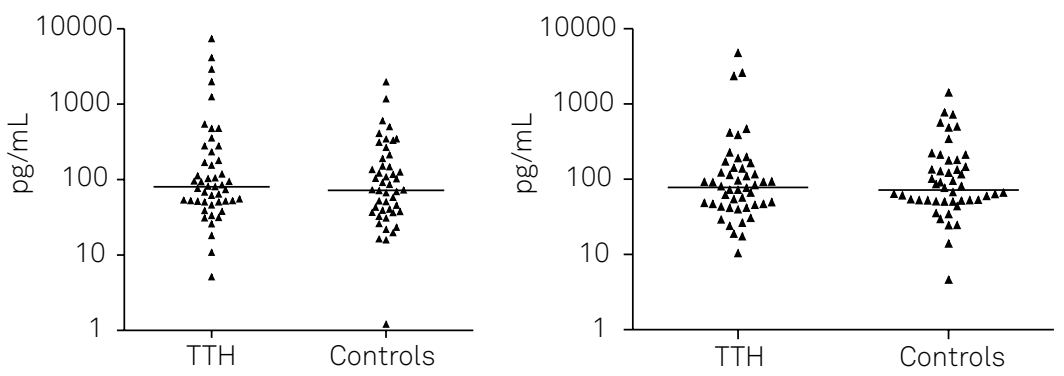

NT3

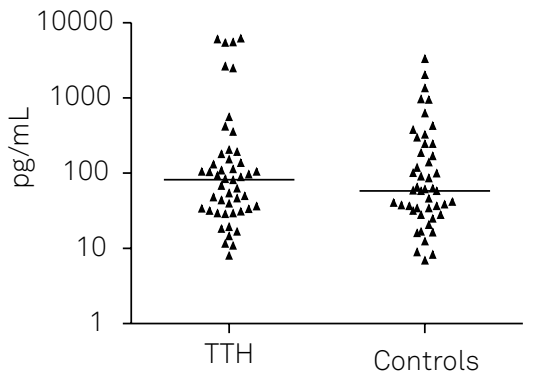

NT4/5

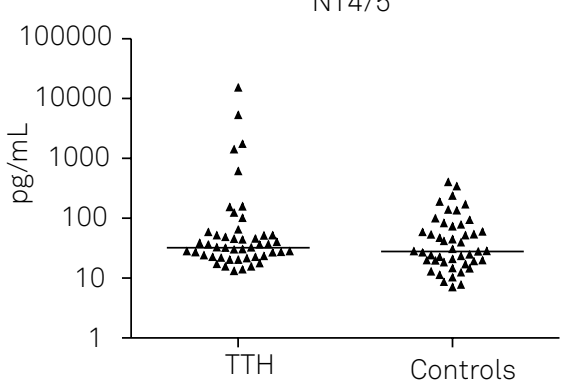

TTH:Tension-type headache; GDNF: Glial cell line-derived neurotrophic factor; BDNF: Brain-derived neurotrophic factor; NGF: Nerve-growth factor; NT: Neurotrophin-3 and neurotrophin-4/5.

Figure. Comparison of neurotrophic factors measures between TTH patients and controls.

Patients with TTH had more anxiety and depressive symptoms than controls. NF levels have been previously correlated with depression and anxiety disorders ${ }^{16,17,18,19,20}$. Despite this, there were no significant correlations among NF levels and anxiety and depression scores, and TTH patients with moderate anxiety and depression scores had not altered $\mathrm{NF}$ levels. One possible explanation for the lack of association in our study is that anxiety and depression were assessed through self-administered inventories, not a formal psychiatric evaluation. Another possibility is that the finding may reflect specific clinical features of the sample. Our population was relatively young and with a predominance of women. Moreover, the proportions of TTH patients with moderate to severe anxiety and depression scores were small. Further studies with larger samples and psychiatric evaluation are needed to confirm the lack of association between NF levels and psychiatric comorbidity in TTH. We found a significant inverse correlation between GDNF, NT-3, and NT-4/5 levels and age. This finding is in line with previous studies showing a decrease in NF levels with increasing age ${ }^{21}$.

Besides the above mentioned limitations, our study was cross-sectional, precluding the establishment of any causal association. The small number of patients with CTTH does not allow definite conclusions regarding whether NF plays a role in TTH chronification.

In conclusion, our data suggest that GDNF, BDNF, NGF, NT-3, and NT-4/5 serum levels are not altered in TTH. Larger and prospective studies are still necessary to confirm this finding and to better assess a potential role for NF in TTH chronification.

\section{ACKNOWLEDGMENTS}

We geatefully aknowledge the contribution of Cássio B. Lacerda and Tarnara Campostrini in data collection.

\section{References}

1. Freitag F. Managing and treating tension-type headache. Med Clin North Am. 2013;97(2):281-92. http://dx.doi.org/10.1016/j.mcna.2012.12.003

2. Chen Y. Advances in the pathophysiology of tension-type headache: from stress to central sensitization. Curr Pain Headache Rep. 2009;13(6):484-94. http://dx.doi.org/10.1007/s11916-009-0078-x

3. Allen SJ, Dawbarn D. Clinical relevance of the neurotrophins and their receptors. Clin Sci (Lond). 2006;110(2):175-91. http://dx.doi.org/10.1042/CS20050161
4. Ossipov MH. Growth factors and neuropathic pain. Curr Pain Headache Rep. 2011;15(3):185-92. http://dx.doi.org/10.1007/s11916-011-0183-5

5. Blandini F, Rinaldi L, Tassorelli C, Sances G, Motta M, Samuele A et al. Peripheral levels of BDNF and NGF in primary headaches. Cephalalgia. 2006;26(2):136-42. http://dx.doi.org/10.1111/j.1468-2982.2005.01006.x

6. Fischer M, Wille G, Klien S et al. Brain-derived neurotrophic factor in primary headaches. J Headache Pain. 2012;13(6):469-75. http://dx.doi.org/10.1007/s10194-012-0454-5 
7. Tanure MT, Gomez RS, Hurtado RC, Teixeira AL, Domingues RB. Increased serum levels of brain-derived neurotropic factor during migraine attacks: a pilot study. J Headache Pain. 2010;11(5):427-30. http://dx.doi.org/10.1007/s10194-010-0233-0

8. Sarchielli P, Alberti A, Floridi A, Gallai V. Levels of nerve growth factor in cerebrospinal fluid of chronic daily headache patients. Neurology. 2001;57(1):132-4. http://dx.doi.org/10.1212/WNL.57.1.132

9. Sarchielli P, Mancini ML, Floridi A, Coppola F, Rossi C, Nardi Ket al. Increased levels of neurotrophins are not specific for chronic migraine: evidence from primary fibromyalgia syndrome. J Pain. 2007;8(9):737-45. http://dx.doi.org/10.1016/j.jpain.2007.05.002

10. Sarchielli P, Gallai V. Nerve growth factor and chronic daily headache: a potential implication for therapy. Expert Rev Neurother. 2004;4(1):115-27. http://dx.doi.org/10.1586/14737175.4.1.115

11. Sarchielli P, Alberti A, Candeliere A, Floridi A, Capocchi G, Calabresi P. Glial cell line-derived neurotrophic factor and somatostatin levels in cerebrospinal fluid of patients affected by chronic migraine and fibromyalgia. Cephalalgia. 2006;26(4):409-15. http://dx.doi.org/10.1111/j.1468-2982.2005.01048.x

12. The international classification of headache disorders 2 nd edition. Cephalalgia. 2004;24(Suppl 1): 8-160.

13. Kosinski M, Bayliss MS, Bjorner JB, Ware Jr JE, Garber WH, Batenhorst A et al. A six-item short-form survey for measuring headache impact: the HIT-6. Qual Life Res. 2003;12(8):963-74. http://dx.doi.org/10.1023/A:1026119331193

14. Beck AT, Epstein N, Brown G, Steer RA. An inventory for measuring clinical anxiety: psychometric properties. J Consult Clin Psychol. 1988;56(6):893-7. http://dx.doi.org/10.1037/0022-006X.56.6.893
15. Beck AT, Ward CH, Mendelson M, Mock J, Erbaugh J. An inventory for measuring depression. Arch Gen Psychiatry. 1961;4(6):561-71. http://dx.doi.org/10.1001/archpsyc.1961.01710120031004

16. Diniz BS, Teixeira AL, Machado-Vieira R, Talib LL, Gattaz WF, Forlenza OV. Reduced serum nerve growth factor in patients with late-life depression. Am J Geriatr Psychiatry. 2013;21(5):493-6. http://dx.doi.org/10.1016/j.jagp.2013.01.014

17. Barbosa IG, Rocha NP, Miranda AS, Huguet RB, Bauer ME, Reis HJ et al. Increased BDNF levels in long-term bipolar disorder patients. Rev Bras Psiquiatr. 2013;35(1):67-9. http://dx.doi.org/10.1016/j.rbp.2012.05.011

18. Fontenelle LF, Barbosa IG, Luna JV, Rocha NP, Miranda AS, Teixeira AL. Neurotrophic factors in obsessivecompulsive disorder. Psychiatry Res. 2012;199(3):195-200. http://dx.doi.org/10.1016/j.psychres.2012.03.034

19. Diniz BS, Teixeira AL, Miranda AS, Talib LL, Gattaz WF, Forlenza OV. Circulating Glial-derived neurotrophic factor is reduced in late-life depression. J Psychiatr Res. 2012;46(1):135-9. http://dx.doi.org/10.1016/j.jpsychires.2011.09.007

20. Barbosa IG, Huguet RB, Neves FS, et al. Impaired nerve growth factor homeostasis in patients with bipolar disorder. World J Biol Psychiatry. 2011;12(3):228-32. http://dx.doi.org/10.3109/15622975.2010.518629

21. Lommatzsch M, Zingler D, Schuhbaeck K et al. The impact of age, weight and gender on BDNF levels in human platelets and plasma. Neurobiol Aging. 2005;26(1):115-23. http://dx.doi.org/10.1016/j.neurobiolaging.2004.03.002 